\title{
Investigation of Cutting Temperature for AISI H13 in High Speed End Milling
}

\author{
Muhammad Riza and Erry Y. T. Adesta
}

Received: 15 September 2016

Accepted: 27 September 2016

Published: 03 October 2016

Publisher: Deer Hill Publications

(c) 2016 The Author(s)

Creative Commons: CC BY

\begin{abstract}
Heat produced at the tool-chip interface during high speed milling operations have been known as a significant factor that affect to tool life and workpiece geometry or properties. This paper aims to investigate cutting temperature behaviours of AISI H13 (48 HRC) under high speed machining circumstances during pocketing. The experiments were conducted on CNC vertical machining centre by using PVD coated carbide insert. Milling processes were done at cutting speeds 150,200 and $250 \mathrm{~m} / \mathrm{min}$ and feed rate were $0.05,0.1$ and $0.15 \mathrm{~mm} / \mathrm{tooth}$. Depths of cut applied were $0.1,0.15$ and $0.2 \mathrm{~mm}$. Tool path method applied in this experiment was contour in. Results presented in this paper indicate that by increasing cutting speed the cutting temperature is lower than low cutting speed. However, by decreasing feed rate leads to cutting temperature low. Cutting temperature phenomena at the corner of pocket milling were also investigated. The phenomena showed that cutting temperature tends to decrease a moment when cutter comes to the corner of pocket and turning point of tool path and increase extremely a moment before leaving the corner and turning point.
\end{abstract}

Keywords: Cutting Temperature, Tool path, AISI H13, High Speed End Milling, Pocketing

\section{INTRODUCTION}

End milling is a basic machining operation in the manufacture of mechanical components to generate a flat surface and/or a three-dimensional free-formed surface; it requires high geometric accuracy and high productivity. During the machining, most of the power consumed for plastic deformation is converted into heat, and high temperatures are generated. High temperature is claimed to cause several types of thermal damage to the cutting tool and workpiece, such as rapid tool wear and thermal expansion of the workpiece [1]. To clarify the influence of temperature on the thermal damage and to select appropriate cutting conditions, good understanding of milling temperatures is required. Since end milling is an intermittent machining process, the cutting tool is depending on cyclical heating and cooling, and temperature variation in the cutting tool is more complicated than in turning. The achievement of these objectives by high speed end milling places it at the front line of rapid tooling and manufacturing technologies.

One of the important parameters to optimize cutting conditions is cutting temperature during milling of Inconel 718. This conditions is applicable for dry machining of difficult-to-cut materials. The thermocouple should be placed as close as possible to the cutting zone to get accurate measurement result [2].

Among three cutting parameters, cutting speed was claimed as the most influence parameter in temperature rise. It was found that between two temperature devices used during the experimental work, infrared pyrometer generated higher cutting temperature reading than embedded thermocouple. It is due to the ability of infrared pyrometer records all factors involved (workpiece, cutting tool and especially chips temperature) during machining operation [3]. The increase of machining parameters such as cutting speed and feed rate implicate increase of cutting temperature during end milling of $\mathrm{Al} \mathrm{6063.} \mathrm{It} \mathrm{was} \mathrm{found} \mathrm{that} \mathrm{the} \mathrm{relation} \mathrm{between} \mathrm{feed} \mathrm{rate} \mathrm{and} \mathrm{depth} \mathrm{of} \mathrm{cut} \mathrm{are}$ significant [4]. Depth of cut is claimed as the most influential factor affect to surface temperature during machining of AISI 1020 medium carbon steel. Surface roughness increases as feed rate increased and such condition leads to workpiece temperature decreases. A better surface quality can be achieved in higher cutting temperature condition

Riza, M1. and Adesta, E.Y.T ${ }^{1,2}$ 区

'Faculty of Engineering, International Islamic University Malaysia, Kuala Lumpur 53100, Malaysia

${ }^{2}$ Agile and Sustainable Manufacturing Research Unit (ASMARU)

E-mail: eadesta@iium.edu.my 
during machining. Cutting temperature in this research can be used as a predictor of cutting performance [5]. The higher negative angles of tool holder is, the higher cutting force becomes. Simultaneously, cutting temperature rises in line with the rises of cutting force. It causes tool wear occurred rapidly and effect to reduction of cermet inserts life [6].

Dr. Carl Salomon [7] in 1931 revealed that there is a specific cutting speeds area where machining is difficult to be performed because of heat generated is extremely high. Therefore, high-speed machining is also known as cutting speeds beyond that limit. Generation of similar tool temperature at two different cutting speed can be done at both conventional and high speed machining. This condition is thoroughly shown in Figure 1. Two different cutting speed is indicated by $V_{a}$ (conventional speed) and $V_{b}$ (high speed) which produce the same life of cutting tool. The tool temperature decreases when the cutting speed moves further area of b resulting in "unlimited" life of cutting tool [7, 8]. By applying up milling technique, temperature recorded increases gradually during the cutting period and the highest cutting temperature is achieved right after machining process end during milling of Ti-6Al-4V. Oppositely, by applying down milling technique, the cutting temperature increases rapidly just after cutting process begun and decrease during the cutting. It is clear that significant temperature rise occurred when down milling is applied compared to up milling technique [8].

A number of researches $[2-6,8]$ have been carried out around cutting temperatures and much important understanding has been gained. However, the cutting temperature of AISI H13 in high speed end milling by considering cutting temperature at the corner of pocket has not been explored. Cutting temperature at the corner of pocket plays significant role to ensure that geometrical accuracy and surface quality is satisfied.

\section{Experimental Details}

The workpiece material used in this research was $\mathrm{H} 13$ steel that is hardened and tempered to $48 \mathrm{HRC}$. The dimensions of the workpiece were $130 \times 100 \times 30 \mathrm{~mm}$. Cutting tool $20 \mathrm{~mm}$ in diameter was utilized in pocketing process. The cutting tool accommodate two indexable inserts in every single cutting process. Each surface was milled using a fresh cutting edge. The CoroMill 490 insert tools were securely installed to the tool holder.

The milling processes were carried out on CNC vertical machining center Mazak Nexus 410A-II CNC Mill without any cutting fluid. These experiments adapted contour-in direction tool path strategies. Contour in tool path strategy described as the path movement of tool during milling along the boundary, creating a window frame-like milling path towards the centre. Figure 2 shows contour-in tool path strategy.

Milling processes were conducted at cutting speeds 150,200 and $250 \mathrm{~m} / \mathrm{min}$. with feed rate were $0.05,0.1$ and $0.15 \mathrm{~mm} /$ tooth. Depths of cut involved were $0.1,0.3$ and $0.5 \mathrm{~mm}$ for every milling process. All the process and parameters were programmed in CNC programming. There are two devices attached to machine while experiment conducted that are dynamometer and thermal camera. The dynamometer is supported by its devices such as charge amplifier, signal conditioning and signal analyser to measure cutting force. Thermal camera on the other hand equipped by image analyser to measure cutting temperature. Figure 3 and Figure 4 show experimental setup and experimental procedure.

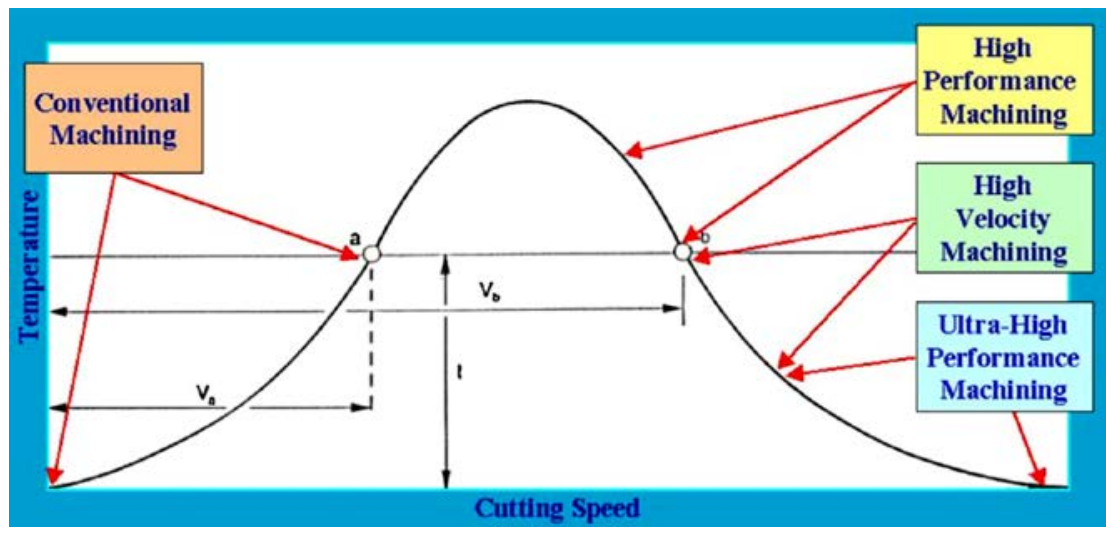

Figure 1: High speed machining diagram $[7,8]$. 
TP1

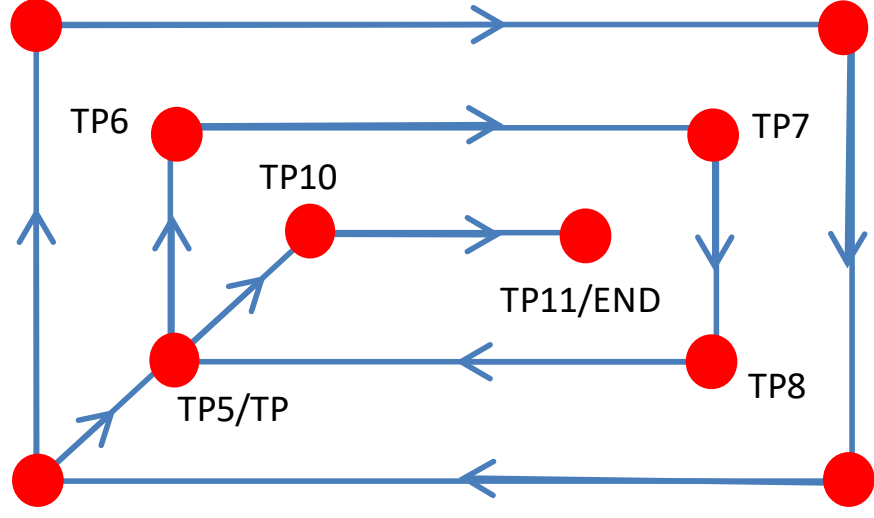

TP2

TP3

START /TP4

Figure 2: Contour-in tool path strategy.

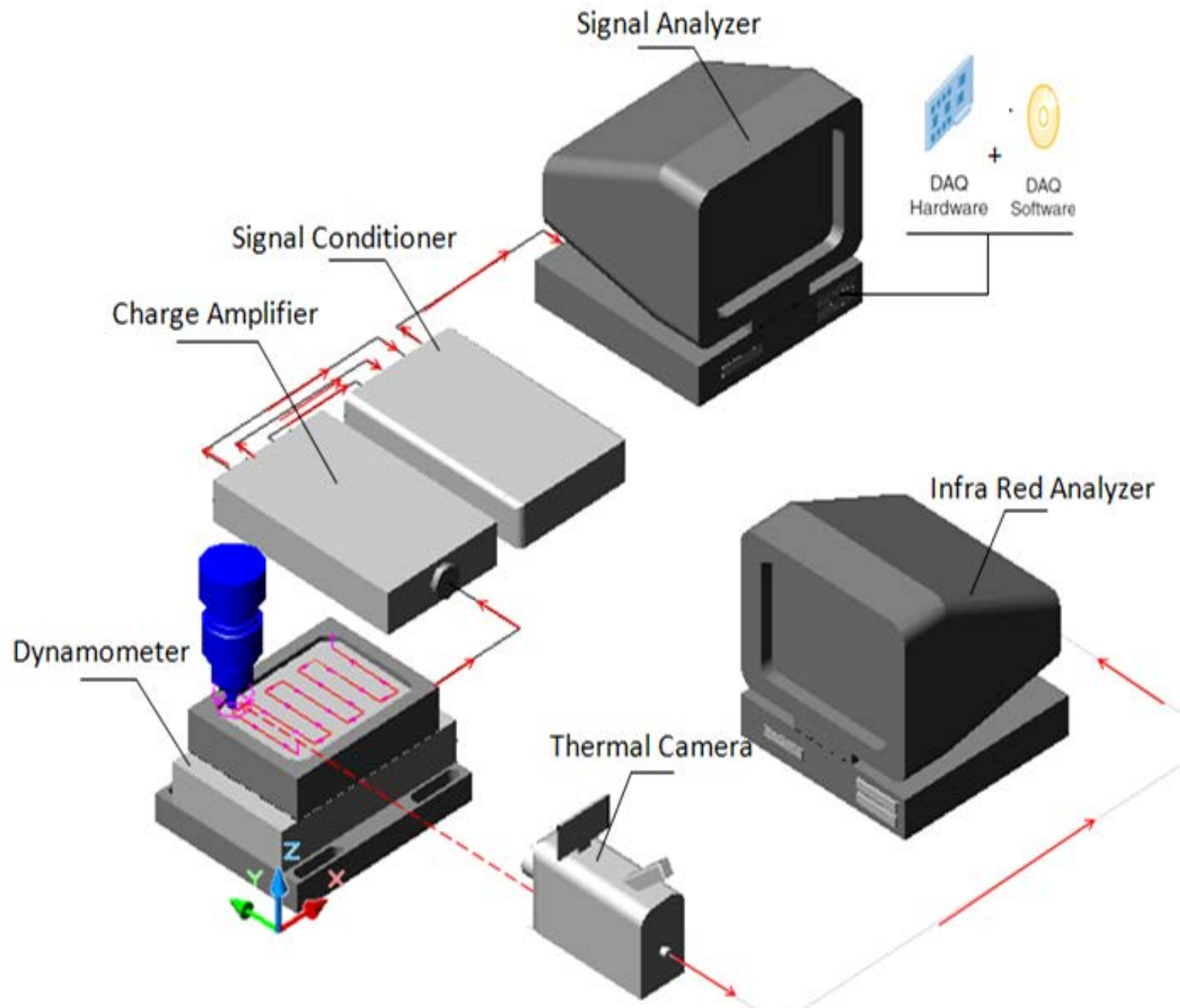

Figure 3: Schematic diagram of experimental setup. 


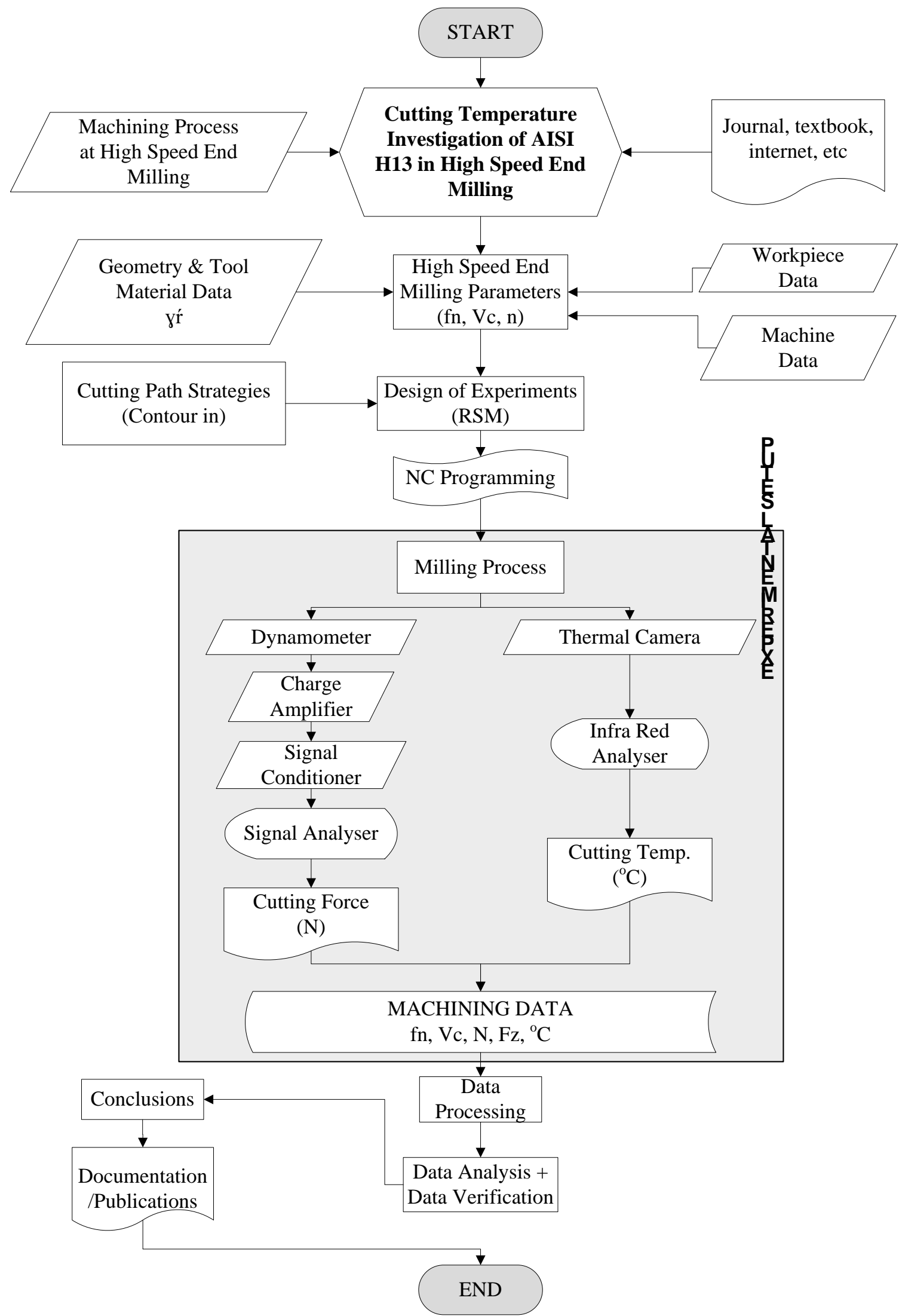

Figure 4: Schematic of experimental procedure. 


\section{RESULTS AND DISCUSSIONS}

\subsection{Cutting Temperature of AISI H13}

The cutting temperature of this experiment was measured by ThermoPro (Model TP8) Infrared (IR) thermal imaging camera. Infra red photograph taken can be seen in Figure 5. The effect of an increase cutting speed on cutting temperature is illustrated in Figure 6. It can be seen that cutting temperature tend to increases signifacntly until cutting speed reached $200 \mathrm{~m} / \mathrm{min}$. The range of cutting temperature for cutting speed $200 \mathrm{~m} / \mathrm{min}$ and below is between $317.4^{\circ} \mathrm{C}$ to $920.9^{\circ} \mathrm{C}$. Once cutting speed reachs into $250 \mathrm{~m} / \mathrm{min}$ the cutting temperature decline drastically. The cutting temperature in this area is between $104.6^{\circ} \mathrm{C}$ to $132.2^{\circ} \mathrm{C}$. Cutting temperature average at speed of below 200 $\mathrm{m} / \mathrm{min}$ is $649.4^{\circ} \mathrm{C}$ and drop significantly to $117.4^{\circ} \mathrm{C}$ when speed of $250 \mathrm{~m} / \mathrm{min}$ is applied. The ratio of cutting temparature under $200 \mathrm{~m} / \mathrm{min}$ is $82 \%$ higher than speed of $250 \mathrm{~m} / \mathrm{min}$. It can be observed that beyonf the area of cutting speeds tested, the surface temperature increased with cutting speed and obviously there is reduction at higher speeds occurred. This approach is similar to what has been discovered by Salomon [7] and contrary with McGee's findings [9]. McGee has found that temperature rised paralleled cutting speed untill a maximum which was the same with the workpiece melting point. Refer to what has been concluded by Dewes (1999) about Salomon's curve that the there is the highest point at middle of cutting speed curve when cutting speed beyond this point, the cutting temperature decreases at higher cutting speed. Figure 6 revealed that at speed of $200 \mathrm{~m} / \mathrm{min}$ the cutting temperature reaches its highest point. It can be considered that cutting temperature at speed up to $200 \mathrm{~m} / \mathrm{min}$ as the peak cuttting temperature and at speed of $250 \mathrm{~m} / \mathrm{min}$ is the turn down point of cutting temperature where the lowest cutting temperature is $104.6^{\circ} \mathrm{C}$. It is agreeable with Salomon's hypotesis.

Declination of cutting temperature may be caused by the force produced from the cutting process. As figured out in Figure 6 that the cutting force is higher at cutting speed of below $200 \mathrm{~m} / \mathrm{min}$. compared to cutting speed of 250 $\mathrm{m} / \mathrm{min}$. At cutting speed of below $200 \mathrm{~m} / \mathrm{min}$ the cutting force is $153 \mathrm{~N}$ in average while at cutting speed of 250 $\mathrm{m} / \mathrm{min}$ the force produced was $132 \mathrm{~N}$. The cutting temperature begins decline at speed $200 \mathrm{~m} / \mathrm{min}$. with $650^{\circ} \mathrm{C}$ in average. It can be concluded that the melting point of AISI $\mathrm{H} 13$ is up to $650^{\circ} \mathrm{C}$ in average and may be workpiece materials begin to lose their strength and can be cut without difficulty. This is results in cutting energy produced is decreased with the increase of cutting speed.

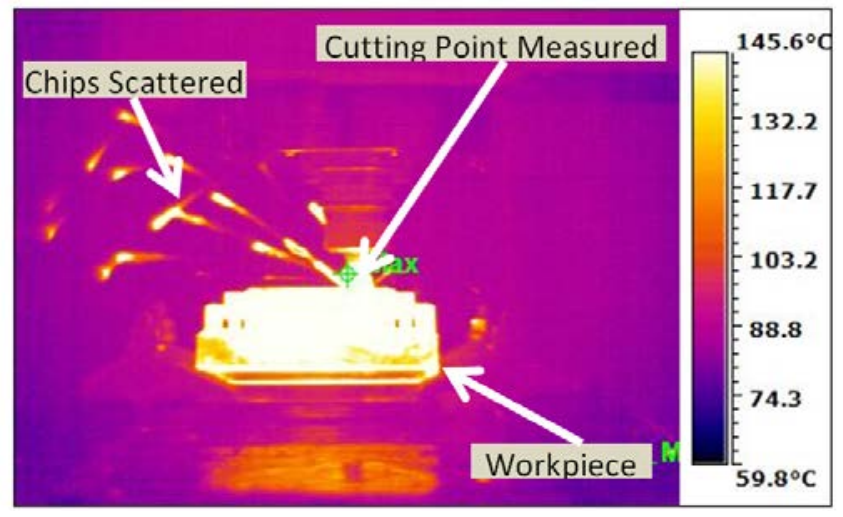

Figure 5: Infrared photograph of cutting process $\left(V_{c}=200 \mathrm{~m} / \mathrm{min}, V_{f}=0.1 \mathrm{~mm} /\right.$ tooth, DoC $\left.=0.2 \mathrm{~mm}\right)$.

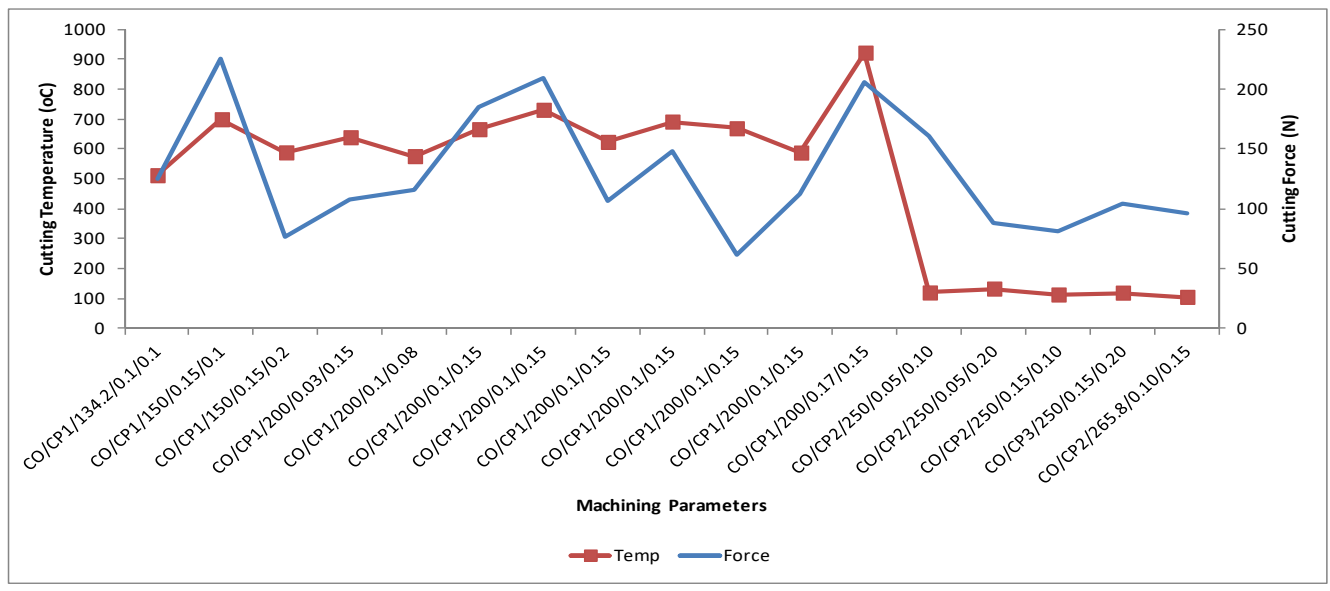

Figure 6: Cutting temperature and cutting force variation in machining of AISI H13. 


\subsection{Effect of Machining Parameters on Cutting Temperature}

3.2.1 Effect of Cutting Speed on Cutting Temperature

The results obtained give a understandable idea about values of temperature achieved at high speed end milling process. Cutting forces were measured to evaluate and to justify the cutting temperature produced in machining processes. Figure 7 shows effect of cutting speed in relation to cutting temperature and cutting force in contour-in path strategy. This figure evidence that at the lower cutting speed, cutting temperature produced is high. When cutting speed reached $150 \mathrm{~m} / \mathrm{min}$ the cutting temperature is $587^{\circ} \mathrm{C}$ and turn down drastically to $120^{\circ} \mathrm{C}$ at speed 250 $\mathrm{m} / \mathrm{min}$. This is due to heat produced during milling process at low cutting speed engaged with workpiece longer than at high cutting speed. The chips produced at high speed is released faster than low speed.

\subsubsection{Effect of Feed Rate on Cutting Temperature}

Figure 8 illustrates the effect of feed rate in relation to cutting temperature and cutting force in contour-in path strategy. This figure revealed that feed rate produce lower cutting force and cutting temperature at lower condition. This is because at the lower feed rate, contact time between cutting tool and workpiece is longer than high feed rate. It gives enough time for cutting tool and workpiece to produce heat. At feed rate setup to $0.05 \mathrm{~mm} /$ tooth cutting temperature and cutting force are $328^{\circ} \mathrm{C}$ and $136 \mathrm{~N}$ respectively. At feed rate of $0.15 \mathrm{~mm} /$ tooth the cutting temperature increased $75 \%\left(1427^{\circ} \mathrm{C}\right)$ as effect of incremental of force produce by this feed rate that is $408 \mathrm{~N}$.

\subsubsection{Effect of Depth of Cut on Cutting Temperature}

Figure 9 demonstrates the effect of depth of cut in relation to cutting temperature and cutting force in contour-in path strategy. The figure below illustrated that in high speed end milling where contour in path strategy applied, the highest cutting temperature and cutting force is at depth of cut of $0.15 \mathrm{~mm}$. This is because the deeper depth of cut is, the larger contact area between cutting tool and workpiece (depth of cut).

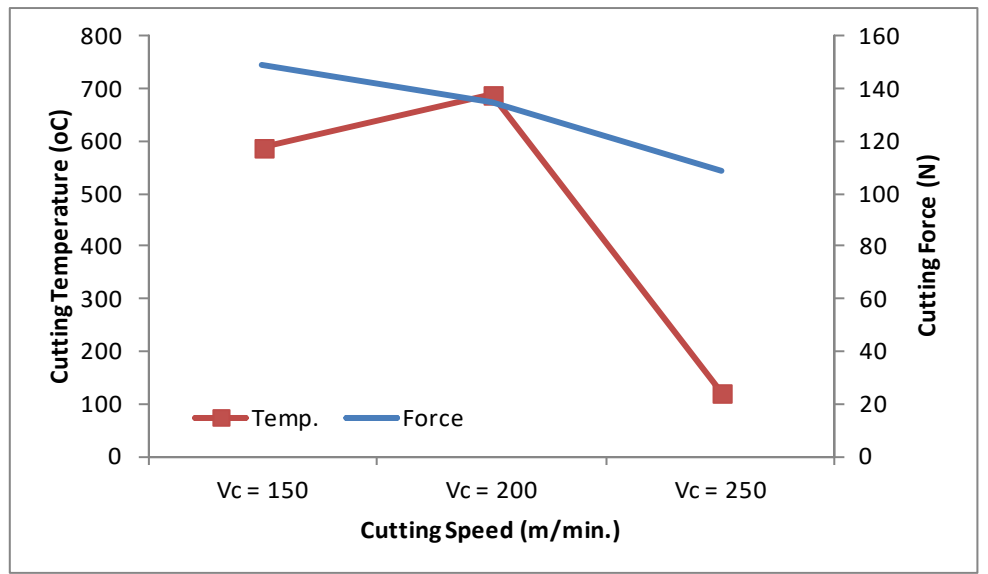

Figure 7: Effect of cutting speed in relation to cutting temperature and cutting force in contour-in path strategy.

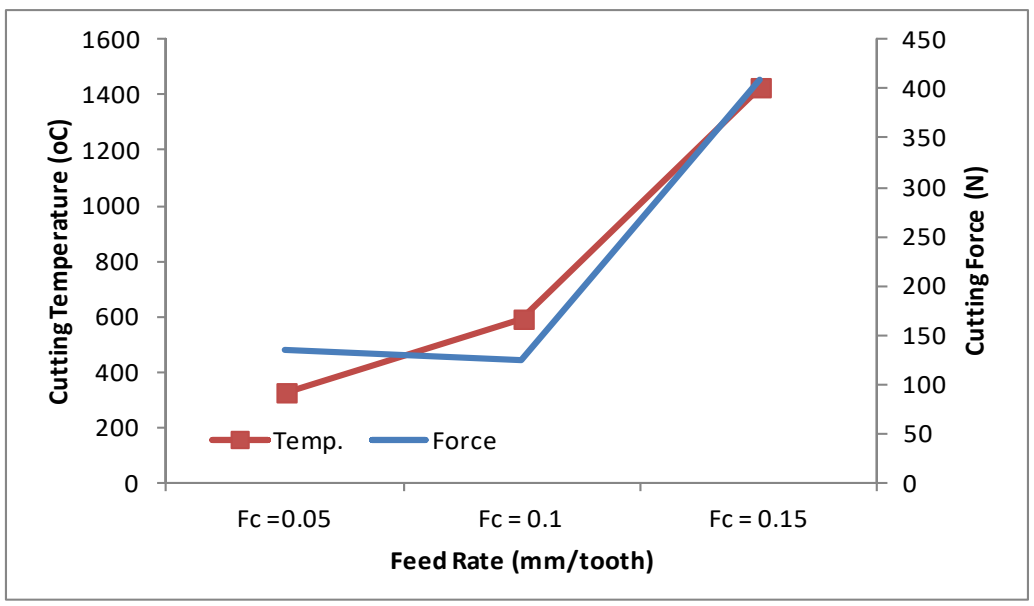

Figure 8: Effect of feed rate in relation to cutting temperature and cutting force in contour-in path strategy. 


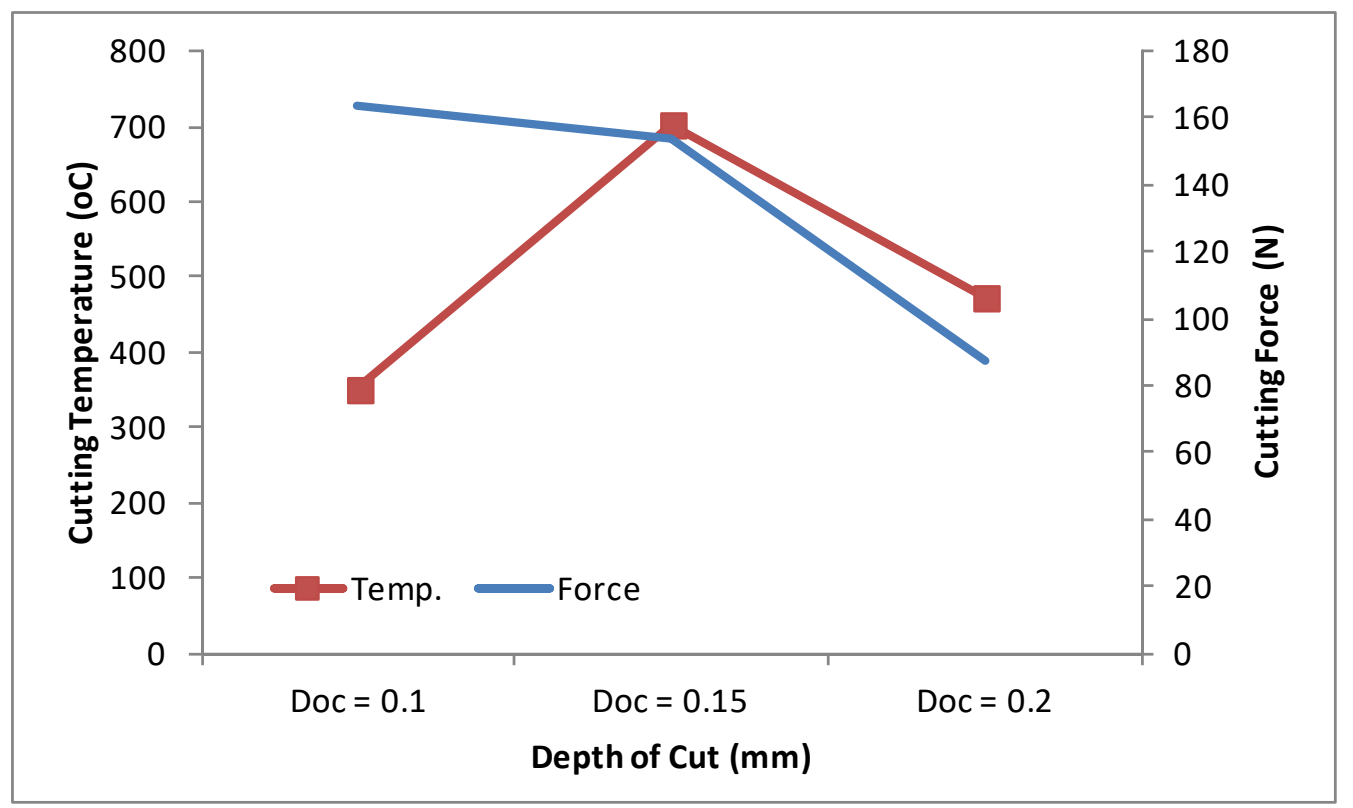

Figure 9: Effect of depth of cut in relation to cutting temperature and cutting force in contour-in path strategy.

\subsection{Cutting Temperature at the Corners of the Pocket}

The behaviour of cutting temperature at the corner of pocket and at the turning point of tool path is shown in Figure 10 apparently. Cutting temperature when cutter engaged with pocket or turning point is relative low. A few moments since the cutter engage the pocket or turning point, the temperature at that corner becomes higher. As seen in Figure 10 , a moment when cutter comes to Turning Point 1 (TP1) the temperature is $449.8^{\circ} \mathrm{C}$ and right after 1 second tremendously rise up to $1163.7^{\circ} \mathrm{C}$. It is more than $200 \%$ temperature incremental by only hang about in TP1 by 1 second. The same behaviour occurred at TP2. Temperature at TP2 that is when cutter reached this point for the first time is $758.1^{\circ} \mathrm{C}$ and increases sharply to $1287^{\circ} \mathrm{C}$ in the next second of time. This is because the table speed needs to be slowed down to give chance the table changing the cutting in accordance with the tool path. As consequence of this action, motor of CNC milling machine experiences a temporary stop before cutting tool turn the feed direction. Since the spindle speed unchanged thus it can generates friction and heat, excessively. If the heat produced is very far above the tolerance demands, the workpiece machined may be getting burning marks or even start to burn as a result of this heat.

\section{CONCLUSIONS}

In this research, the development of latest study about cutting temperature and cutting force were studied. Effect of machining parameters in relation to cutting temperature and cutting force in the pocket's corner in contour-in path strategy were highlighted. The important finding can be concluded as follows:

1. Cutting temperature increases as cutting speed is increased. However, at the higher level of cutting speed ( $250 \mathrm{~m} / \mathrm{min}$.) the cutting temperature of AISI H13 turn down. It is agreeable with Salomon's hypothesis.

2. Feed rate $\left(F_{c}\right)$ play a significant causes augmentation of cutting temperature and cutting force in high speed end milling when countur-in tool path applied.

3. Cutting temperature when cutter engaged with pocket or turning point is relative low. A few moments since the cutter engage the pocket or turning point, the temperature at that corner becomes higher than previous. This is because the table speed needs to be slowed down to give chance the table changing the direction in accordance with the tool path. As consequence of this action, motor of CNC milling machine experiences a temporary stop before cutting tool turn the feed direction.

4. In general, fluctuate of cutting force cause rise and fall of cutting temperature in machining processes during the experiment. The cutting force is related to the cutting temperature.

\section{ACKNOWLEDGEMENT}

With deep grief and condolence, the authors would like to acknowledge the contribution of PhD Candidate Mohamad Yuhan Suprianto who passed away in Mecca during his pilgrimage. Without his contribution this research would not be successful. We pray to almighty Allah to place him in the haven with His myriads of bounties. 


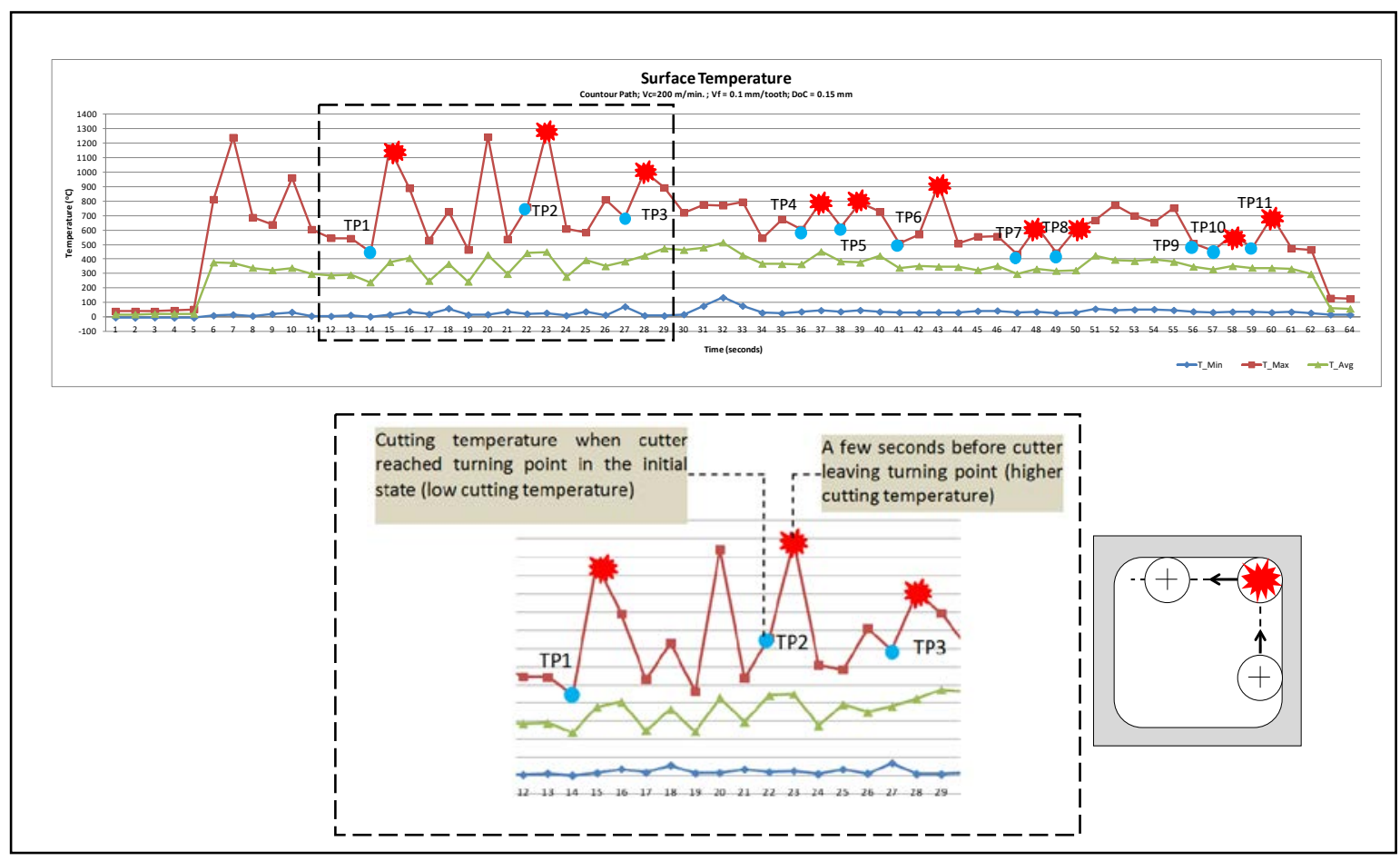

Figure 10: Temperature history of AISI H13 at the corner $\left(V_{c}=250 \mathrm{~m} / \mathrm{min}, V_{f}=0.15 \mathrm{~mm} /\right.$ tooth, DoC $\left.=0.20 \mathrm{~mm}\right)$.

\section{REFERENCES}

1. Sato, M., Tamura, N., \& Tanaka, H. (2011). Temperature variation in the cutting tool in end milling. Journal of Manufacturing Science and Engineering, 133(2), 021005.

2. Coz, G. L. \& Dudzinski, D. (2014). Temperature variation in the workpiece and in the cutting tool when dry milling Inconel 718. International Journal of Advanced Manufacturing Technology, 74(5), 1133-1139.

3. Fata, A. G. J. (2011). Temperature measurement during machining depending on cutting conditions. P\&A Science and Technology, 1(2), 16-21.

4. Sivasakthivel, P. S., \& Sudhakaran, R. (2013). Optimization of machining parameters on temperature rise in end milling of Al 6063 using response surface methodology and genetic algorithm. International Journal of Advanced Manufacturing Technology, 67(9), 2313-2323.

5. Suhail, A. H., Ismail, N., Wong, S. V. \& Jalil, N. A. A. (2011). Workpiece surface temperature for in-process surface roughness prediction using response surface methodology. Journal of Applied Sciences, 11(2), 308-315.

6. Adesta, E. Y. T., Riza, M., \& Ali, M. Y. (2012). Cutting force impact to tool life of CT5015 in high speed machining by applying negative rake angles. Applied Mechanics and Materials, 117-119, 633-638.

7. Salomon, C. J. (1931). Process for machining metals of similar acting materials when being worked by cutting tools. German patent: 523594.

8. Longbottom, J. M., \& Lanham, J. D. (2006). A review of research related to Salomon's hypothesis on cutting speeds and temperatures. International Journal of Machine Tools \& Manufacture, 46(14), 1740-1747.

9. McGee, F. J. (1979). High speed machining study: methods for aluminium workpieces. American Machinist, 121126. 